\title{
Assistência de enfermagem no trauma raquimedular: uma revisão integrativa da literatura
}

\author{
Nursing care in spinal cord trauma: an integrative literature review \\ Asistencia de enfermería en trauma raquimedular: una revisión bibliográfica integradora \\ Gabriela Santos Oliveira ${ }^{1}$, Kennia Rodrigues Tassara ${ }^{1}$, Lívia Vieira Simões Ansaloni', Pedro \\ Henrique Ataides de Moraes ${ }^{1 *}$, Ricardo Ansaloni de Oliveira ${ }^{1}$, Paulienne Ramos da Silva Matias ${ }^{1}$.
}

\section{RESUMO}

Objetivo: Compreender e retratar a assistência de enfermagem prestada a pacientes vítimas de trauma raquimedular. Métodos: Trata-se de uma revisão integrativa da literatura, por meio da análise de pesquisas que abordavam acerca da temática proposta no período de publicações entre 2009 a 2019. Resultados: A revisão demostrou que o enfermeiro se torna protagonista no cuidado ao paciente, atuando frente as necessidades e no planejamento de cuidados específicos e individualizados ao paciente vítima de Trauma Raquimedular (TRM) e a sua família, o que exige do profissional a contínua busca de conhecimento acerca dos três momentos que o paciente enfrenta: o pós-trauma imediato, a hospitalização e a reabilitação. Considerações finais: Torna-se fundamental, portanto, que o profissional de enfermagem busque se atualizar permanentemente, a fim de garantir um melhor plano de cuidados, sendo integralizado e individualizado de acordo com as necessidades do mesmo, lhe assegurando uma melhor adaptação as limitações impostas e a sua reinserção na sociedade.

Palavras-chave: Avaliação em enfermagem, Emergências, Traumatismos da medula espinhal.

\begin{abstract}
Objective: Understanding and portray the nursing care provided to patients victims of raquimedular trauma. Methods: This is an integrative review of the literature, through the analysis of research on the theme proposed in the period of publications between 2009 and 2019. Results: The review showed that the nurse become a protagonist in patient care, acting according to the needs and planning of specific and individualized care for Spinal Cord Injury (SCI) patients and their families, which requires the professional to continuously seek knowledge about the three moments that the patient faces: the immediate post-trauma, hospitalization, and rehabilitation. Final considerations: It become fundamental, therefore, the nursing professional seeks to be permanently updated, in order to guarantee a better care plan, being integralized and individualized according to his needs, assuring him a better adaptation to the imposed limitations and his reinsertion in the society.
\end{abstract}

Key words: Evaluation in nursing, Emergencies, Spinal cord trauma.

\section{RESUMEN}

Objetivo: Comprender y representar los cuidados de enfermería prestados a los pacientes víctimas de traumatismos raquimedulares. Metodos: Se trata de una revisión integradora de literatura, a través del análisis de las investigaciones sobre el tema propuesto en el periodo de publicaciones entre 2009 y 2019 . Resultados: La revisión demostró que la enfermera se convierte en protagonista de los cuidados del paciente, actuando de acuerdo con las necesidades y la planificación de los cuidados específicos e individualizados al paciente víctima de una Lesión Medular (LME) y a su familia, lo que exige que el profesional busque continuamente el conocimiento de los tres momentos que se enfrenta el paciente: el post-trauma inmediato, la hospitalización y la rehabilitación. Consideraciones finales: Se vuelve fundamental, por lo tanto, que el profesional de enfermería busque estar permanentemente actualizado, para garantizar un mejor plan de cuidados, siendo integrado e individualizado de acuerdo con las necesidades del paciente, asegurándole una mejor adaptación a las limitaciones impuestas y su reintegración a la sociedad.

Palabras clave: Evaluación en enfermería, Emergencias, Traumatismo de la médula espinal.

${ }^{1}$ Centro Universitário de Goiatuba (UNICERRADO), Goiatuba - GO.
${ }^{\star}$ E-mail: pedrohenriqueataidesdemoraes@gmail.com 


\section{INTRODUÇÃO}

O Trauma Raquimedular (TRM) decorre de um evento traumático muitas vezes ocasionado por acidentes automobilísticos e moto ciclísticos, lesões por armas de fogo e armas brancas, queda de altura, e até mesmo por mergulho em águas rasas. Corresponde a interrupção dos tratos nervosos, sensoriais e motores da medula em quaisquer porções estruturais (ligamentar, medular, discal, óssea, radicular ou vascular) o que resulta na insuficiência parcial ou total das funções (NATIONAL ASSOCIATION OF EMERGENCY MEDICAL TECHNICIANS, 2017).

lutaka AS, et al. (2014) mencionam que uma lesão na coluna não diagnosticada ou manejada de forma incorreta pode culminar em um déficit neurológico permanente, podendo comprometer as funções e a qualidade de vida do paciente, ou até mesmo resultar em risco de vida. Dessa forma, abordam que o atendimento adequado deve ser iniciado ainda no local do acidente, com imobilização cuidadosa da coluna cervical e transporte adequado do paciente a uma unidade de emergência.

Os autores supracitados ainda evidenciam que as lesões medulares estão comumente associadas a outras lesões, onde $80 \%$ têm probabilidade de apresentar uma lesão em outros órgãos e $41 \%$ têm probabilidade de apresentar traumatismo cranioencefálico (TCE). Além do fato de a lesão medular reduzir a probabilidade de um paciente sobreviver a hospitalização inicial e alcançar boa função e qualidade de vida, apresentando-se com uma taxa de mortalidade de 17\% à hospitalização inicial (IUTAKA AS, et al., 2014).

O indivíduo acometido por tal lesão sofre grandes modificações psicomotoras e psicológicas durante o processo de aceitação da sua condição atual. Diante da deficiência física adquirida perde-se mais que os movimentos do corpo, modificam-se também autonomia, perspectivas sobre o futuro, posição no trabalho, hábitos diários e responsabilidades (MOREIRA RB e SOUZA AM, 2017).

Perante a gravidade do TRM, o indivíduo acometido enfrenta um longo período de hospitalização e recuperação, podendo surgir nesse processo inúmeras complicações do quadro como trombose venosa profunda, bexiga neurogênica, intestino neurogênico, lesões por pressão, pneumonias, diminuição do tônus muscular e choque neurogênico, sendo necessário e importante a presença do enfermeiro nesse processo para minimizar ou até mesmo evitar essas complicações (SOUSA EPD, et al., 2013).

Assim, como bem leciona Cavalcante ES e Miranda FAN (2014), analisar a assistência na perspectiva da complexidade do TRM demonstra a importância da execução de ações bem planejadas, com treinamento de toda equipe que atende às vítimas. Faz-se relevante ainda considerar a todo o planejamento desse cuidado o contexto da família envolvida nesse processo, além de toda uma vida produtiva que o paciente tinha, e que, com uma adequada assistência, pode voltar a ter, mesmo que, com limitações. Torna-se importante considerar que a assistência ao paciente vítima de TRM, diante da complexidade do quadro, e das mudanças que o mesmo enfrentará durante todo o período de aceitação e adaptação da lesão, é um grande desafio à equipe de enfermagem, o que exige do profissional a necessidade de conhecimento em todas as fases que permeiam o processo de aceitação, reabilitação e readaptação do paciente.

Diante do exposto, o estudo em tela teve como objetivo compreender e retratar, conforme a literatura científica publicada, a assistência de enfermagem prestada a pacientes vítimas de TRM.

\section{MÉTODOS}

Com vista ao alcance do objetivo proposto, optou-se por uma revisão integrativa da literatura, desenvolvida em base de material já publicado referente ao tema proposto. A pesquisa foi iniciada a partir da definição do tema e estipulação do período de publicação das fontes, tendo como pergunta norteadora: De qual forma a assistência de enfermagem é prestada às vítimas de TRM?

Em seguida, foi realizado o levantamento bibliográfico utilizando as bases de dados Base de Dados Nacionais da Enfermagem (BDENF), Biblioteca Regional de Medicina (BIREME), Biblioteca Virtual em Saúde (BVS), Literatura Latino-Americana e do Caribe em Ciências da Saúde (LILACS), Scientific Eletronic Library Online (SciELO) e Anais do III Congresso Brasileiro de Ciências da Saúde. Os descritores em Ciências da 
Saúde (DeCS) utilizados para coleta de dados foram: "Cuidados de Enfermagem", "Traumatismos da Medula Espinhal", "Protocolos de Enfermagem", "Papel do profissional de enfermagem" e "Emergências".

Foram atribuídos os seguintes critérios para seleção dos artigos: sendo as seguintes categorias (revisão de literatura, original, reflexão, atualização, relato de experiência etc.). Desse modo, os artigos com resumos e textos completos disponíveis para análise foram utilizados para o processo de inclusão; aqueles publicados no idioma português, entre os anos 2009 e 2018. Logo, em relação ao critério de exclusão dos artigos foi: os estudos que não atendessem os critérios de inclusão mencionados.

Da amostra obtida, resultou em 63 potenciais artigos, assim procedeu-se à leitura detalhada de cada resumo e artigo, logo foram selecionados aqueles que se enquadravam ao objetivo proposto pelo presente estudo, a fim de organizar e tabular os dados encontrados. Dessa maneira, para a organização e tabulação dos dados, os pesquisadores elaboraram instrumento de coleta de dados contendo: título, periódico, ano de publicação, autor, natureza do estudo, objetivo, método de análise, resultados. Seguindo os critérios de inclusão, 19 publicações foram selecionadas para análise, conforme mostra a Figura 1.

A partir da análise foi possível extrair os conceitos delineados em cada artigo e os interesses dos pesquisadores para a construção do estudo proposto. Desse modo, os trabalhos foram agrupados e comparados por relevância de similaridade dos conteúdos, sob a forma de categorias empíricas, assim sendo proposto três categorias para análise, especificadas como: a relevância do enfermeiro no atendimento préhospitalar a vítimas de TRM, a atuação da equipe de enfermagem durante o período de hospitalização dos pacientes com TRM, e a importância da enfermagem na reabilitação da pessoa com lesão medular.

Figura 1 - Fluxograma de seleção dos artigos.

Descritores: Cuidados de Enfermagem, Traumatismos da Medula Espinhal, Protocolos de Enfermagem, Papel do profissional de enfermagem e Emergências. / Estudos identificados nas Bases de Dados ( $n=63$ )

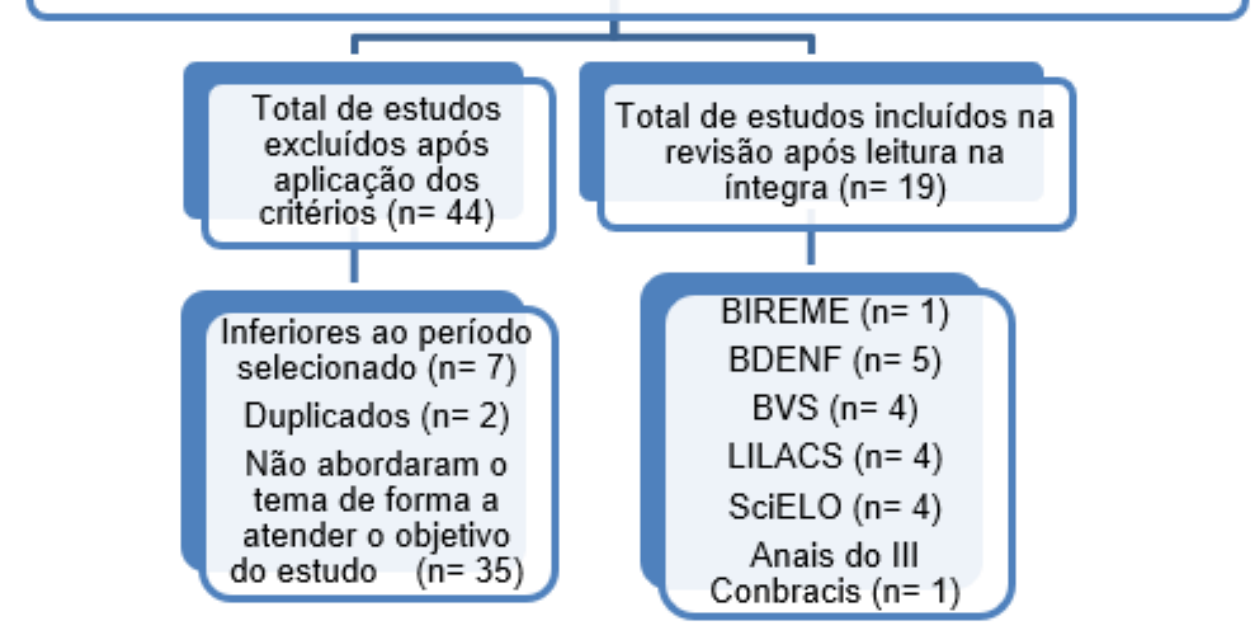

Fonte: Oliveira GS, et al., 2021.

\section{RESULTADOS}

A amostra dessa revisão integrativa resultou, em números percentuais, em $26,4 \%$ dos artigos estavam na BDENF, 5,3\% na BIREME, $21 \%$ na BVS, $21 \%$ na LILACS, $21 \%$ na SciELO, e por fim $5,3 \%$ dos Anais do III Conbracis.Levando em consideração o ano de publicação, no ano de 2009 obteve 10,5\%, no ano de 2010 $10,5 \%$, no ano de $20125,3 \%$, no ano de $201326,4 \%$, no ano de $201415,7 \%$, no ano de $20155,3 \%$, no ano de $20165,3 \%$, no ano de 2017 15,7\% e no ano de 2018 5,3\%. Não foi encontrada nenhuma publicação do ano de 2011 que fosse pertinente ao estudo. No desenvolver da pesquisa, os resultados foram organizados de acordo com o proposto pela temática encontrada em cada um dos artigos, de modo que contribuísse para um melhor tratamento e análise dos dados, conforme serão apresentados no Quadro 1. 
Quadro 1 - Características dos artigos incluídos neste estudo, de acordo com os autores, ano de publicação, objetivo e resultados.

\begin{tabular}{|c|c|c|}
\hline Autores / Ano & Objetivo & Resultados \\
\hline Adão RS e Santos MR, 2012. & $\begin{array}{l}\text { Descrever as ações do enfermeiro em unidade básica e } \\
\text { avançada no APH móvel. }\end{array}$ & $\begin{array}{l}\text { O enfermeiro é responsável pela assistência integral ao } \\
\text { paciente, educação continuada dos colaboradores e elaboração } \\
\text { de protocolos próprios de atendimento. }\end{array}$ \\
\hline Bernardes A, et al., 2014. & $\begin{array}{l}\text { Analisar como ocorre a supervisão do enfermeiro em um } \\
\text { Serviço de Atendimento Móvel de Urgência de um município } \\
\text { do estado de São Paulo. }\end{array}$ & $\begin{array}{l}\text { Os resultados revelaram que a supervisão foi considerada } \\
\text { primordial nesse serviço. }\end{array}$ \\
\hline Carreno I, et al., 2015. & $\begin{array}{l}\text { Caracterizar a equipe de atendimento pré-hospitalar no } \\
\text { interior do Rio Grande do Sul. }\end{array}$ & $\begin{array}{l}\text { A equipe é formada por } 52 \% \text { são técnicos de enfermagem, } \\
29,5 \% \text { médicos e } 18,2 \% \text { são enfermeiros. }\end{array}$ \\
\hline Cyrillo RMZ, et al., 2009. & $\begin{array}{l}\text { Identificar os diagnósticos de enfermagem em vítimas de } \\
\text { trauma atendidas em um Serviço de Atendimento Móvel de } \\
\text { Urgência no interior do estado de São Paulo. }\end{array}$ & $\begin{array}{l}\text { Identificar os diagnósticos de enfermagem possibilita aos } \\
\text { enfermeiros detectar e controlar os riscos precocemente e } \\
\text { planejar individualmente o cuidado prestado a esses pacientes } \\
\text { por meio de intervenções específicas capazes de proporcionar } \\
\text { ações eficazes e imediatas. }\end{array}$ \\
\hline Leal SDP, et al., 2017. & $\begin{array}{l}\text { Discutir e descrever as regiões neuroanatômicas envolvidas } \\
\text { no TRM correlacionando com seus aspectos fisiopatológicos } \\
\text { e com a atenção médica no atendimento pré-hospitalar. }\end{array}$ & $\begin{array}{l}\text { O conhecimento da cinemática do trauma bem como a } \\
\text { neuroanatomia é fundamental para o planejamento de toda } \\
\text { assistência á saúde. }\end{array}$ \\
\hline Lima MKS e Júnior JSA, 2018. & $\begin{array}{l}\text { Enfatizar a importância do conhecimento teórico-prático dos } \\
\text { profissionais para entender a importância do controle } \\
\text { adequado da coluna para evitar lesões secundárias. }\end{array}$ & $\begin{array}{l}\text { Se fazem necessárias técnicas adequadas para favorecer a } \\
\text { vítima uma reabilitação sem sequelas ou ao menos reduzir as } \\
\text { lesões advindas do trauma em questão. }\end{array}$ \\
\hline O'Dwyer G, et al., 2016. & $\begin{array}{l}\text { Analisar a implantação do Serviço de Atendimento Móvel as } \\
\text { Urgências (SAMU) no estado do Rio de Janeiro. }\end{array}$ & $\begin{array}{l}\text { O processo de implantação do SAMU no estado foi marcado por } \\
\text { tensões políticas e fragilidades de gestão e coordenação. }\end{array}$ \\
\hline Silva DS, et al., 2014. & $\begin{array}{l}\text { Analisar as contribuições das pesquisas sobre liderança de } \\
\text { enfermagem no contexto dos serviços de } \\
\text { urgência/emergência no período de } 2001 \text { a } 2012 \text {. }\end{array}$ & $\begin{array}{l}\text { É necessário investimento na comunicação e formação dos } \\
\text { enfermeiros para o exercício da liderança. }\end{array}$ \\
\hline
\end{tabular}




\begin{tabular}{|c|c|c|}
\hline Autores / Ano & Objetivo & Resultados \\
\hline Albuquerque ALP, et al., 2009. & $\begin{array}{l}\text { Compreender os significados das experiências vivenciadas } \\
\text { pelo ser vítima de lesão medular no contexto hospitalar e } \\
\text { descrever as narrativas das experiências vividas. }\end{array}$ & $\begin{array}{l}\text { Foi interpretado como difícil o enfrentamento para o equilíbrio } \\
\text { em si, dado ao rompimento repentino do percurso de suas vidas, } \\
\text { as alterações orgânicas adquiridas que passam a ser motivo de } \\
\text { medos, incertezas, desconforto e ameaça a vida que possuíam } \\
\text { junto a sua família. }\end{array}$ \\
\hline Bertoncello KCG, et al., 2013. & $\begin{array}{l}\text { Identificar os diagnósticos de enfermagem apresentados por } \\
\text { pacientes vítimas de múltiplos traumas e posteriormente, } \\
\text { propor intervenções de enfermagem. }\end{array}$ & $\begin{array}{l}\text { Diante dos principais diagnósticos encontrados, foram propostas } \\
82 \text { intervenções de enfermagem que pudessem propiciar uma } \\
\text { redução de danos a esses pacientes. }\end{array}$ \\
\hline Creôncio SCE, et al., 2013. & $\begin{array}{l}\text { Conhecer o perfil dos enfermeiros atuantes em unidade } \\
\text { hospitalar quanto a abordagem de paciente com TRM. }\end{array}$ & $\begin{array}{l}\text { A maioria dos profissionais refere não estar preparada para } \\
\text { prestar assistência à pacientes com TRM e que as unidades de } \\
\text { ensino superior não abordam de maneira satisfatória a atuação } \\
\text { desses profissionais ao paciente com lesão medular, e é } \\
\text { escassa a promoção de capacitações pelas instituições } \\
\text { hospitalares. }\end{array}$ \\
\hline Lima JPS, et al., 2017. & $\begin{array}{l}\text { Compreender o significado da vivência de internação } \\
\text { hospitalar após diagnóstico de TRM. }\end{array}$ & $\begin{array}{l}\text { O paciente transforma o sentimento de medo, angústia em } \\
\text { vontade de viver, reconhecendo suas limitações e suas } \\
\text { potencialidades. }\end{array}$ \\
\hline Vasconcelos AS, et al., 2013. & $\begin{array}{l}\text { Identificar diagnósticos de enfermagem de acordo com a } \\
\text { taxonomia NANDA, presentes nos sujeitos com lesões da } \\
\text { medula espinhal. }\end{array}$ & $\begin{array}{l}\text { Identificaram-se } 9 \text { diagnósticos, } 12 \text { características definidoras e } \\
29 \text { fatores relacionados de risco. }\end{array}$ \\
\hline $\begin{array}{l}\text { Cavalcante ES e Miranda } \\
\text { FAN, } 2014 .\end{array}$ & $\begin{array}{l}\text { Identificar o conhecimento produzido em âmbito nacional } \\
\text { acerca do TRM e cuidados de enfermagem a essas vítimas. }\end{array}$ & $\begin{array}{l}\text { Foram selecionadas } 41 \text { produções científicas e os resultados } \\
\text { dos estudos encontrados enfatizaram os aspectos } \\
\text { fisiopatológicos e assistenciais de enfermagem na reabilitação } \\
\text { da pessoa com lesão medular. }\end{array}$ \\
\hline Coura AS, et al., 2013. & $\begin{array}{l}\text { Analisar os aspectos contextuais que influenciam a realização } \\
\text { da consulta de enfermagem na visita domiciliar a pessoas } \\
\text { com lesão medular. }\end{array}$ & $\begin{array}{l}\text { O enfermeiro deve desenvolver sua assistência voltadas à } \\
\text { pessoa com lesão medular, levando cada indivíduo e sua família; } \\
\text { e deve-se buscar fortalecer as políticas públicas que defendem } \\
\text { os direitos das pessoas com deficiência. }\end{array}$ \\
\hline
\end{tabular}




\begin{tabular}{|c|c|c|}
\hline Autores / Ano & Objetivo & Resultados \\
\hline França ISX, et al., 2013. & $\begin{array}{l}\text { Medir a qualidade de vida de adultos com lesão medular e } \\
\text { identificar os domínios que prejudicam a qualidade de vida } \\
\text { desses sujeitos. }\end{array}$ & $\begin{array}{l}\text { Os resultados expressam a insatisfação dos investigados com a } \\
\text { qualidade de vida, devendo o enfermeiro contribuir para } \\
\text { reabilitação e reinclusão social da pessoa com lesão medular. }\end{array}$ \\
\hline Lima NBA, et al., 2017. & $\begin{array}{l}\text { Realizar uma busca das produções científicas publicadas a } \\
\text { respeito da importância dos exercícios físicos na promoção } \\
\text { do cuidar multidimensional ao indivíduo paraplégico ou } \\
\text { quadriplégico, assim como investigar os conhecimentos da } \\
\text { enfermagem sobre o benefício de tais atividades e esclarecer } \\
\text { a atuação do enfermeiro na assistência a esses pacientes. }\end{array}$ & $\begin{array}{l}\text { Os pacientes acometidos por lesão medular apresentam déficits } \\
\text { de cuidado e autocuidado. Dessa maneira, constatou-se que a } \\
\text { prática de exercícios oferece diversos benefícios incluindo os } \\
\text { biopsicossociais. }\end{array}$ \\
\hline $\begin{array}{l}\text { Rodrigues FCP e Antunes DA, } \\
2010 .\end{array}$ & $\begin{array}{l}\text { Identificar as condições físicas e emocionais apresentadas } \\
\text { por vítimas de traumas automobilísticos e a atuação possível } \\
\text { do enfermeiro neste contexto. }\end{array}$ & $\begin{array}{l}\text { Constatou-se que a maioria dos pacientes buscou o tratamento } \\
\text { imediatamente e, que após a intervenção terapêutica } \\
\text { ocupacional, eles apontaram vários ganhos, admitindo suas } \\
\text { limitações físicas, e valorizando, sobretudo suas possibilidades. }\end{array}$ \\
\hline Vasconcelos AS, et al., 2010. & $\begin{array}{l}\text { Identificar as intervenções de enfermagem utilizadas na } \\
\text { prática assistencial ao indivíduo com lesão medular no } \\
\text { atendimento pré-hospitalar, hospitalar ou domiciliar. }\end{array}$ & $\begin{array}{l}\text { Verificou-se como intervenções mais prevalentes: posicionar } \\
\text { adequadamente o paciente, mudar decúbito e eliminar pressão } \\
\text { na área lesada, supervisionar eliminações urinárias e intestinais, } \\
\text { inspecionar a pele, realizar cateterismo vesical e lavagem } \\
\text { intestinal e promover higiene. As intervenções voltadas para o } \\
\text { ensino das pessoas com LM e seus familiares com estímulo a } \\
\text { realização do autocuidado são limitadas. }\end{array}$ \\
\hline
\end{tabular}

Fonte: Oliveira GS, et al., 2021. 
A partir das publicações selecionadas no estudo, encontraram-se obras que permeiam três momentos vividos pelo paciente, o pré-hospitalar $(42,1 \%$ das publicações), a hospitalização $(26,3 \%)$ e a fase de reabilitação $(31,6 \%)$. Após o tratamento desses dados e a partir da análise das publicações de 19 artigos que abordavam o TRM resultou em três categorias discutidas a seguir (Figura 2).

Figura 2 - Publicações selecionadas no estudo.

\section{$\square 42,1 \%$ das publicações}

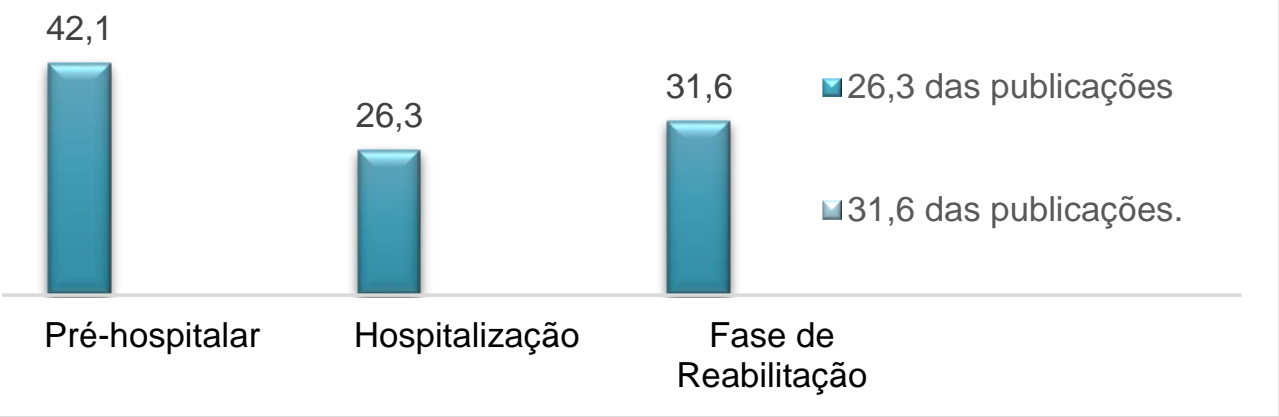

Fonte: Oliveira GS, et al., 2021.

\section{DISCUSSÃO}

Diante da literatura consultada, pode se compreender a relevância da assistência de enfermagem adequada, específica e individualizada em todos os momentos vivenciados pela vítima de TRM. O enfermeiro tem papel de extrema importância no atendimento inicial a essa vítima, bem como pode atuar frente a sua hospitalização e a sua reabilitação, desenvolvendo além do papel de implementador de cuidados, um papel fundamental de educador e incentivador do paciente e familiares (ADÃO RS e SANTOS MR, 2012; CREÔNCIO SCE, et al., 2013; LIMA JPS, et al., 2017; COURA AS, et al., 2013; VASCONCELOS AS, et al., 2010).

E na intenção de investigar acerca da assistência de enfermagem nesse contexto, foram estabelecidas três categorias que permitem melhor compreensão da temática abordada: 1) Atendimento no pré-hospitalar 2) Atuação na hospitalização 3) Enfermagem na reabilitação.

\section{A relevância do enfermeiro no atendimento pré-hospitalar a vítimas de trauma raquimedular}

Nos últimos anos, a enfermagem ampliou consideravelmente o seu campo de atuação no serviço de atendimento pré-hospitalar. Desse modo, torna-se inevitável a exigência do profissional pela busca por aprimoramento constante de seus conhecimentos teórico-práticos e, também o aperfeiçoamento em suas técnicas de liderança, para que assim possa ser refletido em sua atuação com melhor qualidade (CYRILLO RMZ, et al., 2009; O'DWYER G, et al.,2016).

Em consequência desse cenário, o estudo de Bernardes A, et al. (2014) reflete que reduziram os riscos sofridos pelos pacientes ao se depararem com profissionais despreparados para tal atividade, consolidando a enfermagem como uma prática guiada tanto pelo zelo à qualidade do serviço prestado quanto pelos conhecimentos científicos adquiridos em constantes atualizações.

Dada a magnitude do TRM, e principalmente por ser um evento traumático que requer tomada de decisões e intervenções rápidas, é expresso na análise feita por Carreno I, et al. (2015) que o enfermeiro como membro da equipe que prestará o primeiro socorro à vítima é essencial para a condução do atendimento, uma vez que a primeira assistência tem como objetivo principal, amenizar a lesão inicial e não causar lesões secundárias.

É necessário que a equipe esteja preparada para relacionar o mecanismo de trauma as possíveis lesões, favorecendo uma abordagem segura. O que é corroborado por estudo de Leal SDP, et al. (2017), ao pontuarem que deve se suspeitar de TRM em todas as situações que envolvem grande impacto, ausência de cinto de segurança em acidentes automobilísticos, presença de ferimento corto-contuso na região da coluna. 
A realização de uma conduta humanizada e segura é essencial na primeira abordagem. É imprescindível que durante o primeiro contato com o paciente o profissional se apresente adequadamente e acalme a vítima afim de minimizar as sequelas devido o estado de agitação e aflição após o evento traumático, para que assim possa ser realizado nesse momento a estabilização manual da coluna e cabeça com objetivo de evitar agravamento da lesão. Após realizar as intervenções necessárias a individualidade do caso, é preciso cautela ao manusear a vítima durante a imobilização, prossegue-se com o posicionamento do colar cervical e passagem do paciente para prancha rígida, seguida da colocação dos coxins, queixeira e testeira. A equipe deve diminuir o tempo de permanência no local com o objetivo de agilizar o transporte até o hospital de referência para atendimento do caso, e sendo considerada a presença de lesão medular é necessário que a imobilização seja mantida até que o paciente passe por avaliação da equipe médica (LIMA MKS e JÚNIOR JSA, 2018).

Na concepção de Adão RS e Santos MR (2012) a elaboração de protocolos de acordo com a sua realidade, recursos materiais e de pessoal, também é de competência do enfermeiro, sendo importante para garantir maior grau de independência e respaldo nas atividades prestadas, ampliando o seu grau de autonomia, objetivando proporcionar agilidade e otimização do serviço, o que garante eficácia na abordagem e possibilidade mínima de erros.

Sendo assim, a análise de Silva DS, et al. (2014) destaca que cumpre ao enfermeiro a procura por constantes atualizações recorrendo a especializações, e cursos atuando assim como qualificador da assistência prestada. Dessa forma, a educação continuada e permanente, bem como treinamentos e capacitações para utilização dos protocolos pré-estabelecidos para atendimento imediato ao trauma, possibilita uma abordagem segura, individualizada e rigorosa.

Torna-se fundamental, portanto, que o enfermeiro capacite e conduza sua equipe para o reconhecimento da lesão e conhecimento das melhores intervenções no primeiro atendimento ao paciente vítima de TRM, efetivando a tomada rápida de decisões e uma abordagem sincronizada, reduzindo assim o risco de lesões secundárias (ADÃO RS e SANTOS MR, 2012; BERNARDES A, et al., 2014; SILVA DS, et al., 2014).

\section{Atuação da equipe de enfermagem durante o período de hospitalização dos pacientes com trauma raquimedular}

A humanização é indispensável no acolhimento ao paciente vítima de TRM, podendo contribuir para melhor compreensão das necessidades e elaboração de cuidados específicos ao lesado medular, por isso o enfermeiro torna-se protagonista no cuidado a esse paciente (ALBUQUERQUE ALP, et al., 2009; BERTONCELLO KCG, et al., 2013).

É importante a presença da equipe de enfermagem no instante que o paciente recebe a informação de que o mesmo possui uma sequela proveniente da lesão medular, como por exemplo, a paraplegia. Nesse momento faz-se necessário o saber ouvir a fim de conceder conforto físico e emocional ao paciente (ALBUQUERQUE ALP, et al., 2009; LIMA JPS, et al., 2017).

Na pesquisa realizada por Creôncio SCE, et al. (2013) é acrescido, que no momento da hospitalização, cabe ao enfermeiro analisar as particularidades do paciente, diante disso elaborar os diagnósticos de enfermagem e implementar as intervenções pertinentes. Isso deve tornar o tratamento mais eficaz, os procedimentos menos invasivos e o cuidado mais humano.

No que concerne aos diagnósticos de enfermagem, Vasconcelos AS, et al. (2013) expõem em seu estudo de caso, os que são identificados com maior frequência em pacientes com lesão medular são: dor aguda, mobilidade física prejudicada, mobilidade no leito prejudicada, deambulação prejudicada, déficit de autocuidado para banho, déficit de autocuidado para vestir-se, déficit de autocuidado para higiene íntima, déficit de autocuidado para alimentação, integridade da pele prejudicada, incontinência urinária reflexa, integridade tissular prejudicada e padrão respiratório ineficaz.

E nessa perspectiva, outro estudo acrescenta que após a elaboração dos diagnósticos encontrados, o enfermeiro deve analisar suas características definidoras e fatores relacionados, e posteriormente elaborar 
um plano com as intervenções de enfermagem. Isso possibilita ao paciente o cuidado individualizado de acordo com as suas necessidades (BERTONCELLO KCG, et al., 2013).

Considerando que o TRM é uma tragédia repentina que muda abruptamente a vida do indivíduo, o obrigando a reaprender funções básicas do próprio corpo e a lidar com um misto de sentimentos, a análise de Lima JPS, et al. (2017) vem sustentar que durante o período de hospitalização do lesado medular, a equipe que $o$ assiste deve ser altamente preparada para agir com compreensão, paciência e respeito durante a realização dos procedimentos e por toda a permanência dele na instituição.

\section{A importância da enfermagem na reabilitação da pessoa com lesão medular}

O processo de adaptação à nova condição ocorre de maneira lenta e, a família possui papel fundamental como coparticipante frente as necessidades da vítima, de modo que atue com amparo psicológico, oferecendo apoio, paciência e atenção ao ente querido, sendo assim contribuindo com a equipe de enfermagem identificando situações onde o paciente precise de mais assistência (RODRIGUES FCP e ANTUNES DA, 2010). A análise de França ISX, et al. (2013) vem corroborar com essa afirmação ao considerar que o conjunto de ações dos familiares junto a equipe de enfermagem promove uma reabilitação integral e individualizada, a criação de um vínculo com o paciente e a família, o fortalecimento dos laços que irão contribuir no processo de cuidar, e principalmente a integralidade do cuidado durante a reabilitação.

Em relação a um outro aspecto que concerne a menção da importância da atuação de uma equipe multidisciplinar nesse cenário, a pesquisa de Rodrigues FCP e Antunes DA (2010) argumentou e demostrou que durante o processo de reabilitação, uma ação conjunta de profissionais é indispensável, logo a equipe deve ser formada por: médico, fisioterapeuta, psicólogo e enfermeiro, trabalhando juntos com o objetivo de garantir a readaptação integral do indivíduo portador de lesão medular.

A realização da consulta de enfermagem nesse processo também é um importante instrumento para a reabilitação do paciente. Dentre as análises, uma revisão narrativa vem mencionar que durante a visita o enfermeiro deve promover o estímulo a realização de pequenas tarefas do dia-a-dia e o autocuidado, com o objetivo de aumentar a autonomia e estimular o paciente a superar as limitações da sua condição (COURA AS, et al., 2013).

Estudo de Cavalcante ES e Miranda FAN (2014) corrobora com os autores supracitados ao afirmar que o enfermeiro deve orientar o paciente e a família quanto a realização de tarefas que auxiliam na recuperação, e ainda que devem ser proporcionadas ações de ensino-aprendizagem para o cuidado, requerendo de ambos compromisso e paciência.

Com a sistematização da assistência de enfermagem tem-se a garantida e a eficácia das intervenções implementadas durante o processo, o que favorece assim a recuperação, o que logo evita potenciais complicações, e assegura a reinserção do lesado medular na sociedade (VASCONCELOS AS, et al., 2010).

Diante dessas considerações a revisão apresentada por Lima NBA, et al. (2017), faz a reflexão de que a enfermagem deve compreender que a reabilitação não é um processo que visa somente à recuperação motora, mas que favorece a adaptação as limitações impostas, promovendo ao paciente a alcance de um grau maior de autonomia e autoestima.

Os artigos coletados para a produção desta categoria convergem para a importância da enfermagem na assistência ao lesado medular, uma vez que a consulta de enfermagem é usada para identificação das necessidades do paciente e suas particularidades, sendo assim, um ótimo instrumento para que sejam traçadas as condutas que possam facilitar o processo de reabilitação (CAVALCANTE ES e MIRANDA FAN, 2014; COURA AS, et al., 2013; FRANÇA ISX, et al., 2013).

O indivíduo acometido por tal lesão sofre grandes e intensas modificações psicomotoras e psicológicas durante todo o processo de aceitação da sua condição atual, o que indiscutivelmente constitui um grande desafio à equipe de enfermagem, por isso faz-se necessária uma análise mais focada na prestação da assistência em todas as três áreas acima mencionadas: atendimento pré-hospitalar, hospitalização e reabilitação (FRANÇA ISX, et al., 2013; VASCONCELOS AS, et al., 2010). 


\section{CONSIDERAÇÕES FINAIS}

Foi possível identificar por meio dos principais resultados dos estudos, a complexidade da atuação do enfermeiro diante da vítima acometida pelo TRM, uma vez que ele acompanha o paciente desde o momento pós-trauma até a fase de recuperação e readaptação. Mediante os fatos expostos, foi evidenciado o quão imprescindível é a sistematização da assistência de enfermagem na prática clínica para elaboração do plano de cuidado ao paciente, o que garante a continuidade das ações de forma sistematizada e favorece a reabilitação do paciente com lesão medular. Torna-se fundamental, portanto, que o profissional de enfermagem busque se atualizar permanentemente, a fim de garantir um melhor plano de cuidados, sendo integralizado e individualizado, assegurando ao mesmo a possibilidade de adaptação às limitações impostas e sua reinserção na sociedade. Entretanto como limitação do estudo, ressalta-se a escassez de pesquisas voltadas para a abordagem da assistência de enfermagem frente à reabilitação do paciente com lesão medular, com ênfase no cuidado domiciliar. Sendo assim sugere-se, que outras pesquisas busquem o aprofundamento do tema e a compreensão do papel educador do enfermeiro no contexto do paciente com lesão medular.

\section{REFERÊNCIAS}

1. ADÃO RS, SANTOS M.R. Atuação do Enfermeiro no Atendimento Pré-Hospitalar Móvel. Revista Mineira de Enfermagem, 2012; 16(4): 601-608.

2. ALBUQUERQUE ALP, et al. Interpretando as experiências da hospitalização de pacientes com lesão medular. Revista Brasileira de Enfermagem, 2009; 62(4): 552-556.

3. BERNARDES A, et al. Supervisão do enfermeiro no atendimento pré-hospitalar móvel. Revista Eletrônica de Enfermagem, 2014; 16(3): 635-643.

4. BERTONCELLO KCG, et al. Diagnósticos reais e propostas de intervenções de enfermagem para os pacientes vítimas de múltiplos traumas. Revista Eletrônica de Enfermagem, 2013; 15(4): 905-914.

5. CARRENO I, et al. Características da Equipe de Atendimento Pré-Hospitalar no Interior do Rio Grande do Sul. Revista Mineira de Enfermagem, 2015; 19(1): 88-94.

6. CAVALCANTE ES, MIRANDA FAN. Trauma da medula espinhal e cuidados de enfermagem. Revista Brasileira de Pesquisa em Saúde, 2014; 16(1): 125-132.

7. COURA AS, et al. Análise contextual da consulta de enfermagem na visita domiciliar às pessoas com lesão medular. Revista Mineira de Enfermagem, 2013;17(4): 1007-1013.

8. CREÔNCIO SCE, et al. Perfil dos enfermeiros atuantes em um hospital, quanto à abordagem ao traumatismo raquimedular. Revista Online de Pesquisa Cuidado é Fundamental, 2013; 5(4): 599-605.

9. CYRILLO RMZ, et al. Diagnósticos de enfermagem em vítimas de trauma atendidas em um serviço pré-hospitalar avançado móvel. Revista Eletrônica de Enfermagem, 2009; 11(4): 811-819.

10. FRANÇA ISX, et al. Qualidade de vida em pacientes com lesão medular. Revista Gaúcha de Enfermagem, 2013; 34(01): 155-163.

11. IUTAKA AS, et al. Atualização terapêutica: urgências e emergências. 2a ${ }^{a}$. ed. São Paulo: Artes Médicas, 2014.

12. LEAL SDP, et al. Atenção Médica no Atendimento Pré-Hospitalar em TRM Automobilístico: Associação Neuroanatômica Promovendo Qualidade de Vida. Revista Interdisciplinar do Pensamento Científico, 2017; 1(3): 269296.

13. LIMA JPS, et al. Significado da vivência de internação dos pacientes com trauma raquimedular. Revista de Enfermagem UFPE, 2017; 11(Supl. 6): 2527-2532.

14. LIMA MKS, JÚNIOR JSA. A Importância da Imobilização Adequada da Coluna em Vítimas de Trauma Vertebromedular. Anais III CONBRACIS, 2018; 1.

15. LIMA NBA, et al. Importância da mobilidade para tetraplégicos e paraplégicos: implementação dos conhecimentos de enfermagem no cuidar multidimensional. Revista Online de Pesquisa Cuidado é Fundamental, 2017; 9(1): 289-296.

16. MENDES KDS, et al. Revisão integrativa: método de pesquisa para a incorporação de evidências na saúde e na enfermagem. Texto Contexto Enfermagem, 2008; 17(4): 758-764.

17. MOREIRA RB, SOUZA AM. Significados da deficiência adquirida na vida adulta: implicações do trauma raquimedular. Revista Psicologia em Estudo, 2017; 22(2): 243-251.

18. NATIONAL ASSOCIATION OF EMERGENCY MEDICAL TECHNICIANS. PHTLS - Atendimento Pré-hospitalizar ao Traumatizado. 8aㅡ. ed. Burlington: Jones \& Bartlett Learning, 2017.

19. O'DWYER G, et al. Atenção pré-hospitalar móvel às urgências: análise de implantação no estado do Rio de Janeiro, Brasil. Ciência \& Saúde Coletiva, 2016; 21(7): 2189-2200.

20. RODRIGUES FCP, ANTUNES DA. Considerações sobre o paciente com lesão raquimedular ou vítima de trauma: um estudo qualitativo. Revista Eletrônica de Enfermagem, 2010; 13(150): 573-579.

21. SILVA DS, et al. A liderança do enfermeiro no contexto dos serviços de urgência e emergência. Revista Eletrônica de Enfermagem, 2014; 16(1): 211-219.

22. SOUSA EPD, et al. Principais complicações do traumatismo raquimedular nos pacientes internados na unidade de neurocirurgia do Hospital de Base do Distrito Federal. Comunicação em Ciências da Saúde, 2013; 24(04): 321-330.

23. VASCONCELOS AS, et al. Diagnósticos de enfermagem identificados no sujeito com lesão medular. Revista de Enfermagem UFPE, 2013; 7(5): 1326-1332.

24. VASCONCELOS AS, et al. Intervenções de enfermagem nas necessidades básicas da pessoa com lesão medular: revisão integrativa. Online Brazilian Journal of Nursing, 2010; 9(2): 1-11. 